\title{
Multiple Hereditary Exostosis of Distal Ulna with Dislocation of Radial Head: A Case Report
}

\author{
Pamudji Utomo, Mujaddid Idulhaq, Bagus Iman Brilianto \\ Department of Orthopaedics and Traumatology, Prof. Dr. R. Soeharso Orthopaedics Hospital/ \\ Faculty of Medicine, Universitas Sebelas Maret
}

Background: Multiple hereditary exostosis of the forearm is typically formed in the distal ulna causing disturbances in the growth of the ulna and functional disability. Multiple hereditary exostosis inhibits the growth of the ulna leading to an acquisition of a varus deformity in the radius which sometimes leads to dislocation of the radial head, the development of limitations in the pronation-supination of the forearm, and cosmetic problems. The purpose of this study was to reported the multiple hereditary exostosis of distal ulna with dislocation of radial head.

Case Presentation: We present a case of a 14 year-old girl with main complaint of a bony prominence on her right elbow which limits the elbow flexion range of motion. 3D CT-Scan revealed a dislocation of radial head, shortening and posterior bowing of ulna. We performed excision of the prominent radial head, reconstruction, and temporary arthrodesis of the elbow. Results: The forearm deformity in patients with multiple hereditary exostosis related to the crosssectional area of the distal ulnar physis was only one-quarter of the distal radius, the distal ulna is more involved in the condition. There was more longitudinal growth at the distal ulnar physis than at the distal radial physis, the distal ulnar physis contributed more to total Ulnar Length than the distal radial physis did to Radial length. Known surgical interventions including simple excision, ulnar lengthening, corrective radial osteotomy, hemi-epiphyseal stapling of the distal radius, the Sauve-Kapandji procedure.

Conclusion: Simple excision could improve the range of movement of the forearm but would not halt the progression of disease, particularly in younger patients. It was not effective in controlling progression of the deformity. Mature patients did not recur, but in patients that had been excised before puberty the results were varied and unpredictable.

Keywords: multiple hereditary exostosis, radial head dislocation, excision

\section{Correspondence:}

Pamudji Utomo. Department of Orthopaedics and Traumatology Prof. Dr. R.Soeharso Orthopaedics Hospital, Surakarta. Email: utomodr@yahoo.com.

Cite this as:

Utomo P, Idulhaq M, Brilianto BI (2020). Multiple Hereditary Exostosis of Distal Ulna with Dislocationof Radial Head: A Case Report. Indones J Med. 05(01): 63-69. https://doi.org/10.26911/theijmed.2020.05.01.10

cc (†) (2) Indonesian Journal of Medicine is licensed under a Creative Commons

EY NC SA Attribution-NonCommercial-ShareAlike 4.0 International License.

\section{BACKGROUND}

The first description of a patient with multiple exostosis has been attributed to Hunter in 1786. In 1814, Boyer published the first description of a family with multiple hereditary exostosis (MHE). Although exostosis were histological benign lesions, they could cause a variety of clinical problems. Patients with MHE most frequently reported pain, cosmetic concerns and limitations to the adja- cent joint. Deformities of the forearm and wrist occured in $39-59 \%$ of patients with multiple hereditary exostosis. Some commonly seen deformities in this condition were bowing of the radius, shortening of the ulna, ulna drifting of the carpus, and occasionally dislocation or subluxation of the radial head. These complex deformities caused a loss of forearm pronation-supination. 
Recent literature offered divergent views regarding treatment of these deformities. Some recommended aggressive early operative intervention to prevent or reduce the progression of deformities and/or functional impairment, particularly with regard to radial head dislocation. Others stated that these surgical procedures did not produce any predictable functional improvement. Excision of the exostosis might be performed for cosmetic reasons or for resolving local irritation alone.

Acute or gradual lengthening of the ulna, hemiphyseal stapling of the distal aspect of the radius, corrective osteotomy of the radius or excision or open reduction of a displaced radial head might be included in corrective or reconstructive surgery of the forearm.

The most common operation performed in children was simple excision. Fogel et al observed that excision was not effective in controlling the progression of deformity in a series of 10 patients. However, Masada et al demonstrated excellent functional results with simple excision in 2 patients as long as the procedure was limited to those with relative radial shortening secondary to distal of the radius. Wood et al. (1985) demons- trated improved cosmetics after simple excision in 4 patients, but only minimal improvement in rotation of the forearm.

\section{CASE PRESENTATION}

A 14 year-old girl was reffered to our hospital with the main complaint of a bony prominence on her right elbow. She realized the prominence for the first time at the age of 7 and it was getting bigger as she was getting older. But because the prominence never caused any problem for her so she never saw a doctor. Since he prominence on her right elbow started causing problems on her daily schooling activities by limiting the elbow movement, she went to local hospital in which she was referred to our hospital then. There was no history of traumatic event but there was history of the family, her father and her brother had the same complaint. Upon physical examination, we observed a bony prominence on her right elbow with intact skin, no redness or venectasia. There was no tenderness and neurovascular disturbance on the elbow region. Elbow flexion range of motion was $0^{\circ}-120^{\circ}$. There were limitations for supinetion and pronation movements of the right forearm.

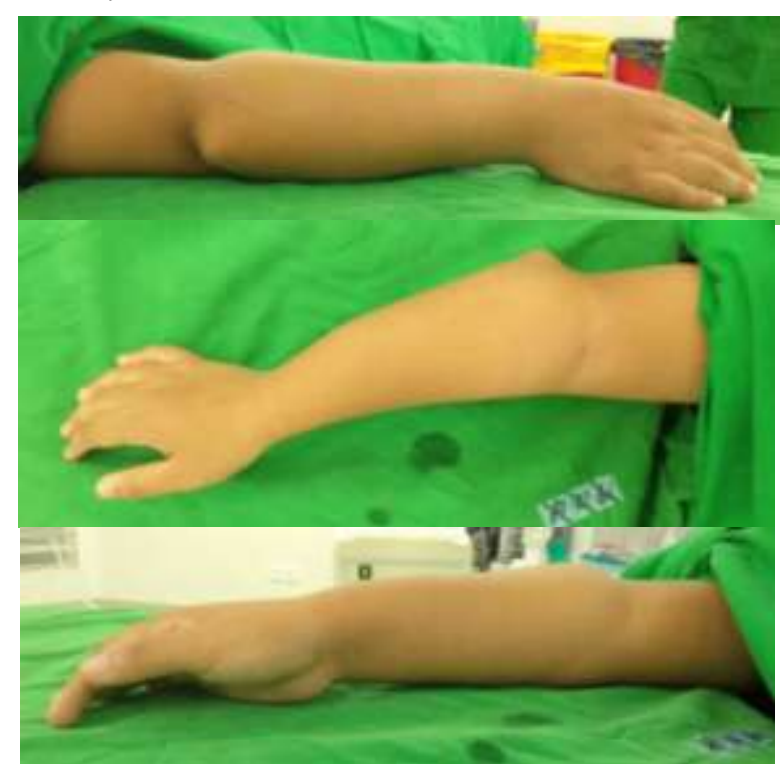

Figure 1. Clinical appearances of patient's right forearm 
Utomo et al./ Clinical profile of manus fracture caused by firecracker blast

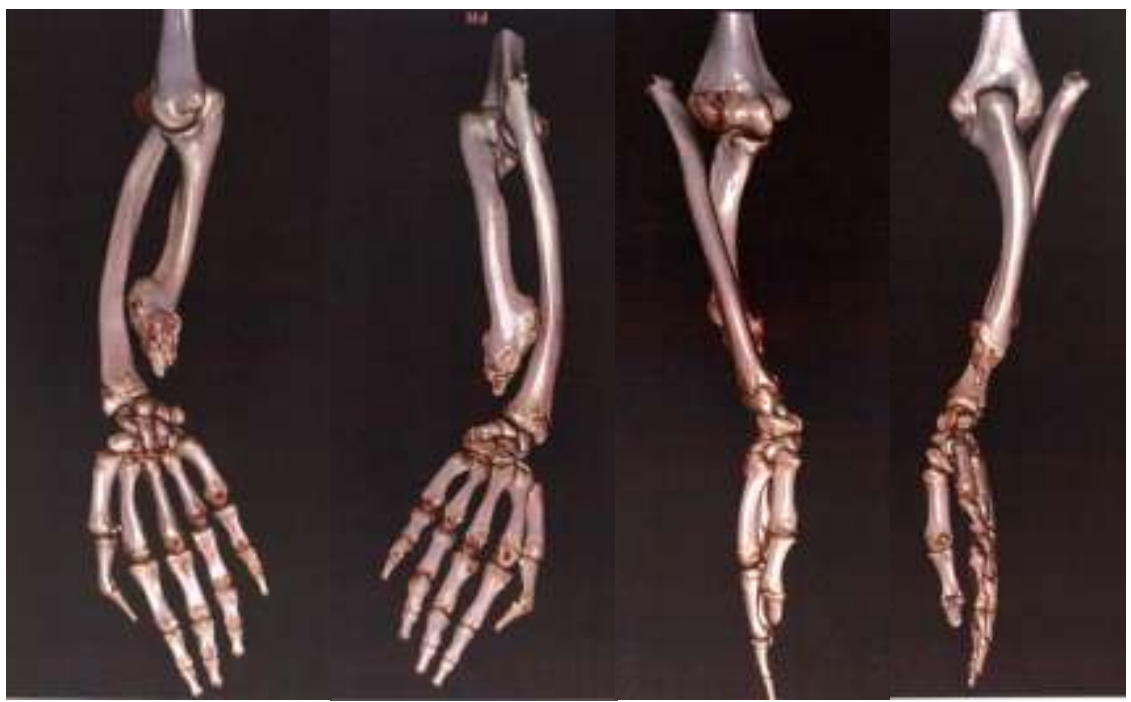

Figure 2. Preoperative 3D CT-Scan of the patient's right forearm

Figure 1 showed clinical appearances of patient's right forearm. Figure 2 showed the 3 D CT-Scan of the Right Forearm revealed a dislocation of radial head, shortening and posterior bowing of ulna. The patient underwent surgery under general anesthesia in our hospital. She was placed in the supine position on the operating table.

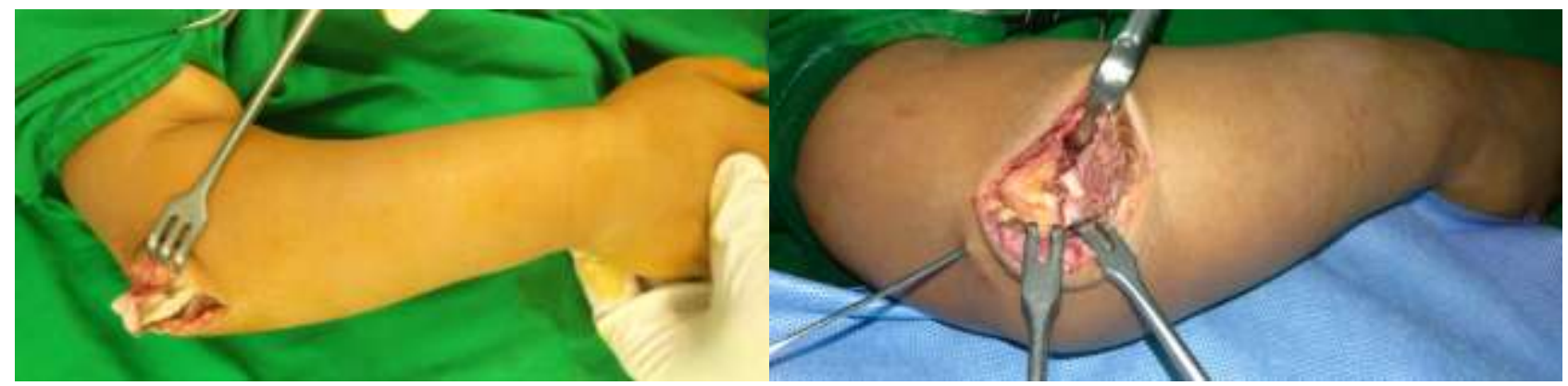

Figure 3. Excision of prominent radial head

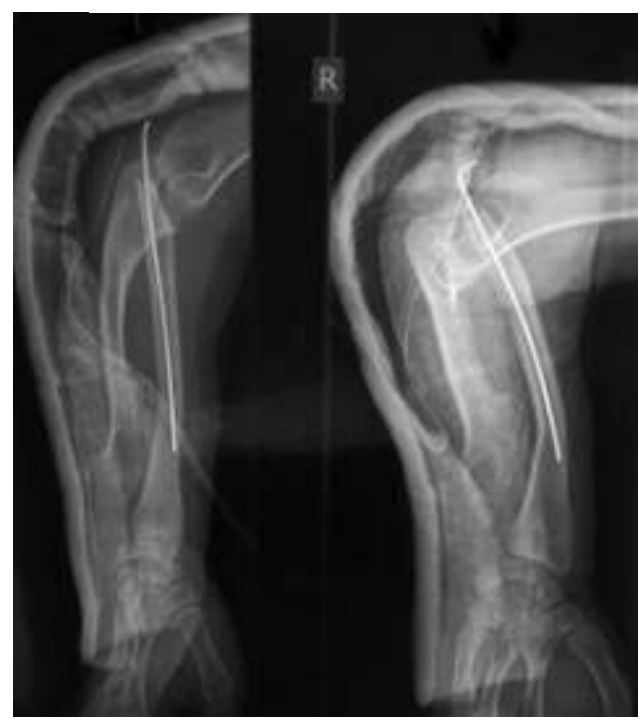

Figure 4. Post operative plain radiograph

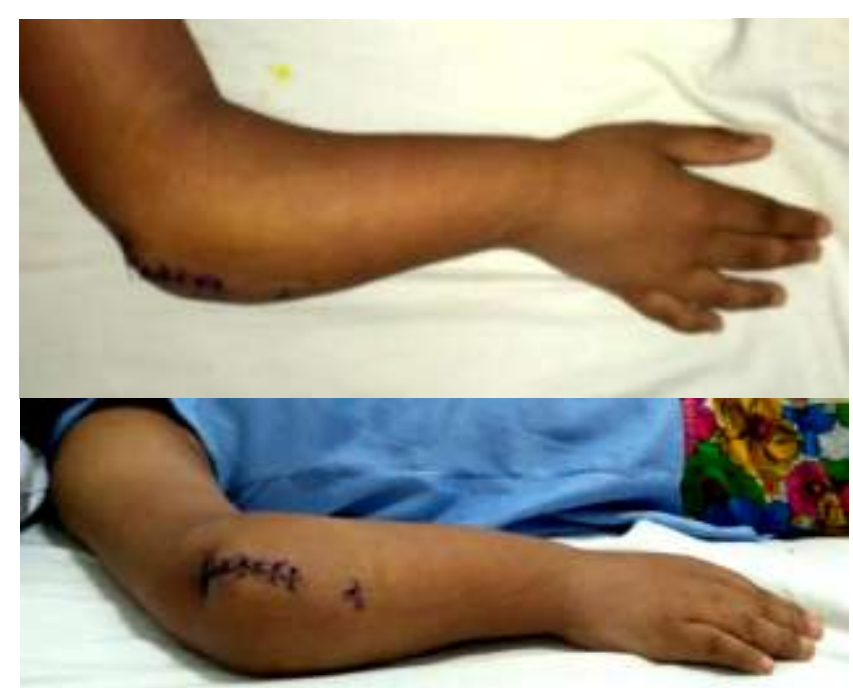

Figure 5. Post operative clinical appearances 
Excision of prominent radial head was performed with osteotomy, and elbow temporary arthrodesis from radius to humeral capitellum was performed with Kirschner wire (Figure 3). Postoperative radiographs revealed anatomical alignment and appropriate position of the radius with excised head (Figure 4).

\section{DISCUSSION}

The pathogenesis of forearm deformities in patients with multiple hereditary exostosis was complex and not yet fully understood. However, there have been several hypotheses to explain this situation. The forearm deformity which was caused by shortening of the ulnar relative to the radius in patients with multiple hereditary exostosis was related to four factors (Rodgers et al., 1993; Schmale et al., 1994; Stanton et al., 1996; Massobrio et al., 2014).

First, the cross-sectional area of the distal ulnar physis was only one-quarter that of the distal radius. The distal ulnar physis being significantly smaller means that its growth could be more severely affected by the disease in the wrist. Second, the distal ulna was more commonly involved in the condition than the distal radius. Third, there was more longitudinal growth at the distal ulnar physis than at the distal radial physis. Finally, the distal ulnar physis contributed more to total Ulnar Length than the distal radial physis did to Radial length. The contribution of the distal ulnar physis compared to the distal radius physis toward the overall growth of the ulna and the radius were 85 and $75 \%$ respectively (O'Hagan et al., 2012; Chimenti and Hammert, 2013; Cheng et al., 2014).

There was evident that although deformities in the upper extremity due to hereditary multiple exostosis were varied, they were well tolerated by most patients. Even when rated solely based on the loss of range of motion, the average physical impairment was slight. Most patients had good preoperative flexion-extension of their wrists and elbows, and motion of forearm pronationsupination was mainly affected.

Objective measurements indicated that the measurable clinical function of the hand was largely preserved within the degree of deformity that was customary for these patients. This certified the adaptability of growing children when they confronted a slowly developing deformity. However, if the radial head was dislocated, significant limitation to the range of motion of the forearm could be observed. Stanton and Hansen reported that a dislocated radial head was significantly associated with a loss of pronation, higher impairment rating, and greater ulnar shortening. It was necessary to treat operatively when the radial head was dislocated (Shin et al., 2006).

Although a number of techniques for the surgical treatment of forearm deformities had been described, the operative treatment for such deformities in patients with multiple hereditary exostosis with radial head dislocation remained unclear (Fogel et al., 1984; Arms et al., 1997; Akita 2007; Ezaki et al., 2012; Mader et al., 2015; Jeuken et al., 2017).

Known surgical interventions included simple excision, acute or gradual ulnar lengthening, corrective radial osteotomy, hemi-epiphyseal stapling of the distal radius, creation of a one-bone forearm and the Sauve-Kapandji procedure (Lluch 2013). The rationale for ulnar lengthening was that the hypoplastic ulna, the keystone of the complex deformity, tethers the radial physis, theoretically diminished ulnar support of the carpus and increased ulnar sided pressure on the radial epiphysis. In the present series, progression of the deformity during the growth period was observed in skeletally immature patients. Exostosis was removed if there was interference with joint movement or if the lesion was prominent, painful, and/or cosme- 
tically undesirable (D'Ambrosi, et al., 2016; Phillips et al., 2018).

Most patients had a combination of these changes. Symptomatic dislocation of the head of the radius was defined as interfering with joint movement (Abe et al., 1996).

The timing of the surgery was extremely important, and there had been some reports regarding this issue. Some recommended early intervention which had more potency for remodelling, leaded to better surgical results (Arms et al., 1997; Ip et al., 2003).

Intervention at older age was sometimes recommended because a recurrent operation could be avoided by postponing the procedure and good function could be acquired despite significant deformity after skeletal maturity (Matsubara et al., 2006; Akita et al., 2007).

Based on the results of this case presentation, it can conclude that simple excision could improve the range of movement of the forearm but would not halt the progression of the disease, particularly in younger patients. Fogel et al. (1984) described simple excision in ten patients and concluded that it was not effective in controlling progression of the deformity. Mature patients did not recur while patients that had been excised before puberty showed various and unpredictable results.

By contrast, other series had shown that simple excision was effective in preventing progression of the disease and improving rotation. Moreover, it helped to control bowing of the radius. Shin et al. (2006) reported the mean supination improved by $11.8^{\circ}$, while pronation did not change appreciably.

Pre-operatively, usually either pronation or supination was affected, with the movement in the other direction being fairly free. Radiological parameters were not significantly altered by excision (Shapiro et al., 1979).
AUTHOR CONTRIBUTION

All authors did excision operative and wrote the manuscript.

\section{CONFLICT OF INTEREST}

The authors declare no conflict of interest in this study.

FUNDING AND SPONSORSHIP

There was no external funding.

\section{ACKNOWLEDGEMENT}

We thank to Prof. Dr. R. Soeharso Orthopaedics Hospital, Surakarta and the patients who gave permission to report this case.

\section{REFERENCE}

Abe M, Shirai H, Okamoto M, Onomura T (1996). Lengthening of the forearm by callus distraction. J Hand Surg Br. 21(2): 151-63. https://doi.org/10.1016/s0266-7681(96)80090-8

Akita S, Murase T, Yonenobu K, Shimada K, Masada K, Yoshikawa H (2007). Longterm results of surgery for forearm deformities in patients with multiple cartilaginous exostoses. J Bone Joint Surg Am. 89(9):1993-9. https://doi.org/10.2106/JBJS.F.01336

Arms DM, Strecker WB, Manske PR, Schoenecker PL (1997). Management of forearm deformity in multiple hereditary osteochondromatosis. J Pediatr Orthop. 17(4): 450-4. https://www.ncbi.nlm.nih.gov/pubmed/9364381

Cheng PG, Chang WN, Lin HS, Wu SK, Wang MN (2014). Traumatic separation of the distal ulnar physis in children: A new classification for displaced volarflexion injuries. $\mathrm{J}$ Orthop Trauma. 28(8): 476-8o. doi: 10.1097/BOT.ooo0000000000060.

Chimenti P, Hammert W (2013). Posttraumatic distal ulnar physeal arrest: a case report and review of the literature 
Utomo et al./ Clinical profile of manus fracture caused by firecracker blast

Hand (NY). 8(1): 115-119. doi: 10.1007/s11552-012-9464-7

D’Ambrosi R, Barbato A, Caldarini C, Biancardi E, Facchini RM (2016). Gradual ulnar lengthening in children with multiple exostoses and radial head dislocation: results at skeletal maturity. $\mathrm{J}$ Child Orthop. 10(2): 127-133. doi: 10.1007/s11832-016-0718-8

Ezaki M, Scott MD, Oishi N (2012). Technique of forearm osteotomy for pediatric problems. The Journal of Hand Surgery. 37(11):2400-2403. https://doi.org/10.1016/j.jhsa.2012.08.033

Fogel GR, McElfresh EC, Peterson HA, Wicklund PT (1984). Management of deformities of the forearm in multiple hereditary osteochondromas. J Bone Joint Surg Am. 66(5): 670-80. https://www.ncbi.nlm.nih.gov/pubmed/6725315

Ip D, Li YH, Chow W, Leong JC (2003). Reconstruction of forearm deformities in multiple cartilaginous exostoses. J Pediatr Orthop B. 12(1): 17-21. https://doi.org/10.1097/01.bpb.0000043728.21564.od

Jeuken RM, Hendrickx RPM, Schotanus MGM, Jansen EJ (2017). Near-anatomical correction using a CT-guided technique of a forearm malunion in a 15-year-old girl: A case report including surgical technique. Orthopaedics \& Traumatology: Surgery \& Research. 103(5): 545. https://doi.org/10.1016/j.otsr.2017.03.017

Lluch A (2013). The Sauvé-Kapandji Procedure. J Wrist Surg. 2(1): 33-40. doi: 10.1055/s-0032-1333465.

Mader K, Koolen M, Flipsen M, van der Zwan A, Pennig D, Ham J (2015). Complex forearm deformities: operative strategy in posttraumatic pathology. Obere Extrem. 10(4): 229-239. doi: 10.1007/s11678-015-0341-1
Masada K, Tsuyuguchi Y, Kawai H, Kawabata H, Noguchi K, Ono K (1989). Operations for forearm deformity caused by multiple osteochondromas. J Bone Joint Surg Br. 71b(1): 24-9. https://doi.org/10.1302/0301-620X.71B1.2914999

Massobrio M, Pellicanò G, Albanese P, Antonietti $G$ (2014). Forearm post-traumatic deformities: classification and treatment. Injury. 45(2): 424-7. doi: 10.1016/j.injury.2013.09.020.

Matsubara H, Tsuchiya H, Sakurakichi K, Yamashiro T, Watanabe $\mathrm{K}$, Tomita $\mathrm{K}$ (2006). Correction and lengthening for deformities of the forearm in multiple cartilaginous exostoses. J Orthop Sci. 11(5): 459-66. https://doi.org/10.1007/s00776-006-1047-4

O'Hagan T, Reddy D, Hussain WM, Mangla J, Atanda A Jr, Bielski R (2012). A complex injury of the distal ulnar physis: a case report and brief review of the literature. Am J Orthop (Belle Mead NJ). 41(1): E1-3. https://www.ncbi.nlm.nih.gov/pubmed/22389897

Phillips L, Aarvold A, Carsen S, Alvarez C, Uglow M (2018). Acute ulnar lengthening for forearm deformity in hereditary multiple exostoses. 98B(15): 9. https://online.boneandjoint.org.uk/doi/abs/10.1302/1358-992X.98BSUPP_15.BSCOS2016-009

Rodgers WB, Hall JE (1993). One-bone forearm as a salvage procedure for recalcitrant forearm deformity in hereditary multiple exostoses. J Pediatr Orthop. 13(5): 587-91. https://www.ncbi.nlm.nih.gov/pubmed/8376557

Schmale GA, Conrad EU, Raskind WH (1994). The natural history of hereditary multiple exostoses. J Bone Joint Surg Am. 76(7): 986-92. https://doi.org/10.2106/00004623-19940700000005 
Utomo et al./ Clinical profile of manus fracture caused by firecracker blast

Shapiro F, Simon S, Glimcher MJ (1979). Hereditary multiple exostoses. Anthropometric, roentgenographic, and clinical aspects. J Bone Joint Surg A. 61(6A): 815-24. https://www.ncbi.nlm.nih.gov/pubmed/225330

Shin EK, Jones NF, Lawrence JF (2006). Treatment of multiple hereditary osteochondromas of the forearm in children: a study of surgical procedures. J Bone Joint Surg Br. 88(2): 255-60. https://-
doi.org/10.1302/0301-620X.88B2.16794

Stanton RP, Hansen MO (1996). Function of the upper extremities in hereditary multiple exostoses. J Bone Joint Surg Am. 78(4): 568-73. https://doi.org/10.2106/00004623-199604000-00010

Wood VE, Sauser D, Mudge D (1985). The treatment of hereditary multiple exostosis of the upper extremity. J Hand Surg Am. 10(4): 505-13. https://doi.org/10.1016/so363-5023(85)80074-5 